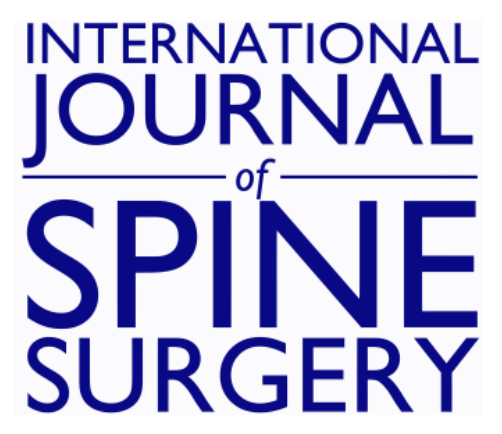

\title{
Restoration of Spinal Motion: Conversion of Anterior Cervical Fusion With Pseudarthrosis to Artificial Disc Replacement
}

\author{
TODD H. LANMAN and JASON M. CUÉLLAR
}

Int J Spine Surg 2020, 14 (4) 483-487

doi: https://doi.org/10.14444/7063

http://ijssurgery.com/content/14/4/483

This information is current as of April 25, 2023.

Email Alerts Receive free email-alerts when new articles cite this article. Sign up at: http://ijssurgery.com/alerts 


\title{
Restoration of Spinal Motion: Conversion of Anterior Cervical Fusion With Pseudarthrosis to Artificial Disc Replacement
}

\author{
TODD H. LANMAN, MD, ${ }^{1,2}$ JASON M. CUÉLLAR, MD, PHD ${ }^{3}$ \\ ${ }^{1}$ University of California, Los Angeles, Department of Neurosurgery, Los Angeles, California, ${ }^{2}$ Cedars-Sinai Medical Center, Department of Neurosurgery, \\ Los Angeles, California, ${ }^{3}$ Assistant Professor, Cedars-Sinai Medical Center, Department of Orthopaedic Surgery, Los Angeles, California
}

\begin{abstract}
Background: Describe the technique and outcomes of the conversion of prior anterior cervical discectomy and fusion (ACDF) with pseudarthrosis to an artificial disc replacement (ADR).

Methods: Case report. Five patients completed the following pain and function questionnaires at baseline and postoperatively: visual analog pain scale (VAS), Neck Disability Index (NDI), PROMIS Emotional Distress-Depression Short Form-4a (P-EDD), PROMIS Pain Interference Short Form 6b (P-PI), and PROMIS Physical Function Short Form-10a (P-SF). Pseudarthrosis was diagnosed using computed tomography imaging of the cervical spine. The level of prior fusion with pseudarthrosis was remobilized after a standard anterior approach was made, and an artificial disc replacement was performed after revision discectomy.

Results: The conversion of fusion to ADR was successful in all 5 patients without intraoperative or postoperative complication or the need to perform revision fusion. The average follow-up duration was 12.4 months (range 624months). VAS improved on average (median) from 6 (6.0) to 2 (2.2), NDI improved from 23 (21) to 15 (17), P-EDD 4a improved from 11 (11) to 4 (4), and P-PI and P-SF improved from 23 (22) to 16 (19) and from 37 (35) to 41 (39.5), respectively. Radiographic range of motion increased at the fusion conversion level from an average of $1^{\circ} \pm 1.2^{\circ}$ to $8.1^{\circ}$ $\pm 4.6^{\circ}$ after the insertion of the artificial disc replacement.

Conclusions: The reversal of ACDF and conversion to an artificial disc replacement is feasible and achieves postoperative range of motion that is similar to that achieved when performed in a segment not previously fused.
\end{abstract}

Cervical Spine

Keywords: cervical disc replacement, cervical disc arthroplasty, total disc arthroplasty, conversion of fusion to disc replacement, motion preservation, motion restoration, spine

\section{BACKGROUND}

Preservation of motion of the cervical spine is becoming more appreciated, with several large major randomized controlled trials demonstrating superiority of artificial disc replacement (ADR) when compared with anterior cervical discectomy and fusion (ACDF) at 5-10 years with a variety of implant designs. ${ }^{1-10}$

High rates of adjacent-segment degeneration (ASD) were originally published by Hilibrand and Robbins $^{11}$ in 2004, reporting clinically significant ASD of $2.9 \%$ per year after ACDF. There is now an extensive and growing body of clinical research evidence demonstrating lower rates of ASD requiring surgery following ADR compared with ACDF.

Lanman et $\mathrm{al}^{6}$ reported adjacent segment surgeries in $12.5 \%$ of patients after 2-level ACDF compared with only $6.5 \%$ after ADR with Prestige-LP at 7 years. Gornet et $\mathrm{al}^{12}$ have recently published the 10-year trial data, reporting an adjacent-segment surgery rate of $17.9 \%$ for the ACDF group compared with only $9 \%$ for the ADR group. Burkus et $\mathrm{al}^{2}$ reported adjacent-segment surgery in $11.9 \%$ of patients after ACDF compared with $4.6 \%$ of patients 7 years after ADR using Prestige. Janssen et $\mathrm{al}^{4}$ reported secondary surgery in $18 \%$ of $\mathrm{ACDF}$ patients compared with $7 \%$ of ADR patients 7 years after ProDisc-C implantation. Similar results were also observed for the long-term follow-up after ADR using the PCM, ${ }^{7}$ Secure-C, ${ }^{10}$ and Mobi- $\mathrm{C}^{9}$ prostheses. A recent meta-analysis of 11 randomized controlled trials evaluating over 2600 patients concluded that adjacent-segment degeneration was statistically significantly lower after ADR compared with ACDF. ${ }^{13}$ 
Table 1. Patient parameters.

\begin{tabular}{|c|c|c|c|c|}
\hline $\begin{array}{l}\text { Patient Age } \\
\text { and Sex }\end{array}$ & Preoperative Diagnosis & $\begin{array}{l}\text { Time Since } \\
\text { Fusion Surgery }\end{array}$ & Procedure & $\begin{array}{l}\text { Most Recent } \\
\text { Follow-Up } \\
\text { Postoperative }\end{array}$ \\
\hline 38 , male & $\begin{array}{l}\text { C5-C6 pseudarthrosis, C4-C5 DDD, } \\
\text { radiculopathy }\end{array}$ & $20 \mathrm{mo}$ & C4-C5 ADR, C5-C6 ADR & $24 \mathrm{mo}$ \\
\hline 26, male & C5-C6 pseudarthrosis & $10 \mathrm{mo}$ & C5-C6 ADR & $14 \mathrm{mo}$ \\
\hline 37, male & C6-C7 pseudarthrosis, C5-C6 DDD & $15 \mathrm{mo}$ & C5-C6 ADR, C6-C7 ADR & 9 mo \\
\hline 62 , male & $\begin{array}{l}\text { C5-C6 and C6-C7 pseudarthrosis, } \\
\text { C3-C4 and C4-C5 DDD }\end{array}$ & $37 \mathrm{mo}$ & $\begin{array}{l}\text { C3-C4 ACDF, C4-C5 ADR, } \\
\text { C5-C6 ADR, C6-C7 ADR }\end{array}$ & $9 \mathrm{mo}$ \\
\hline 38 , male & $\begin{array}{l}\text { C6-C7 pseudarthrosis, C4-C5 } \\
\text { and C5-C6 DDD }\end{array}$ & $7 \mathrm{y}$ & $\begin{array}{l}\text { C4-C5 ADR, C5-C6 ADR, } \\
\text { C6-C7 ADR }\end{array}$ & $6 \mathrm{mo}$ \\
\hline
\end{tabular}

Abbreviations: ACDF, anterior cervical discectomy and fusion; ADR, artificial disc replacement; DDD, degenerative disc disease.

The authors of this study are currently not aware of any previously published reports of technique or follow-up of patients who underwent conversion of prior ACDF with or without pseudoarthrosis to an ADR.

\section{METHODS}

Five patients, aged 26-62, were treated surgically by the removal of anterior cervical plate and screws (if present) and conversion of the fusion to an ADR, using either the ProDisc-C (Synthes, West Chester, PA) or Prestige-LP (Medtronic, Memphis, TN). All of these patients had a suspected pseudoarthrosis at the level of fusion reversal. All cases of pseudarthrosis were diagnosed using computed tomography (CT) imaging of the cervical spine. See Table 1 for patient and surgical information.

\section{Clinical and Radiographic Assessment}

A complete history and physical exam were completed for all patients. Visual analog pain scale (VAS), Neck Disability Index (NDI), PROMIS Emotional Distress-Depression Short Form 4a, PROMIS Pain Interference Short Form 6b, and PROMIS Physical Function Short Form 10a were completed by patients preoperatively and at the most recent postoperative visit. The PROMIS clinical outcome surveys were recently created by the National Institutes of Health as an outcome measure that may be more clinically valid than the traditional NDI and SF-36 questionnaires commonly used and have been validated for cervical spine surgery patients. ${ }^{14,15}$

Preoperative radiographic analysis was performed on all patients, including magnetic resonance imaging (MRI), CT scan, and dynamic radiographs for diagnostic purposes. Postoperative dynamic radiographs were performed, and index level motion was measured before and after surgery on the lateral view.

\section{Surgical Technique}

In all cases, an approach to the anterior cervical spine was made using the interval between the sternocleidomastoid and carotid sheath laterally and the tracheo-esophageal structures medially in the standard Smith-Robinson technique. The prior fusion site was identified, and the previously applied anterior cervical plate and screws were removed if present. A high-speed bur was used under lateral fluoroscopy to excise the prior PEEK cage and/or bone, with caution to avoid removing any vertebral body of either level. In some cases a $1 / 4$-inch flat osteotome was used to develop the plane between the endplate and the PEEK cage. The uncinate processes were partially excised using the high-speed bur, and the bur path was taken in a lateral to medial direction along the native endplates through the bone graft/fusion mass. Lateral fluoroscopy was used to monitor the progress and assist in avoidance of endplate violation. Fluoroscopy can usually delineate the cortical rim of the endplate, but it can still be difficult to know with certainty whether the endplates were not violated intraoperatively. One sign of endplate violation is persistent bleeding from the endplate, which is usually from exposed cancellous bone. If the prior fusion used a PEEK cage that was shown to have some subsidence on preoperative CT scan, then it must be assumed that there had been some endplate violation at this location. Therefore, it is critical to select the implant with the maximum size footprint in order to span the defect and rest on the intact cortical bone of nonviolated endplate more lateral than where the prior graft was seated.

Revision foraminotomy was performed if determined to be necessary based on preoperative MRI and CT scan. Our preference is to excise a significant portion of the foraminal aspect of the 

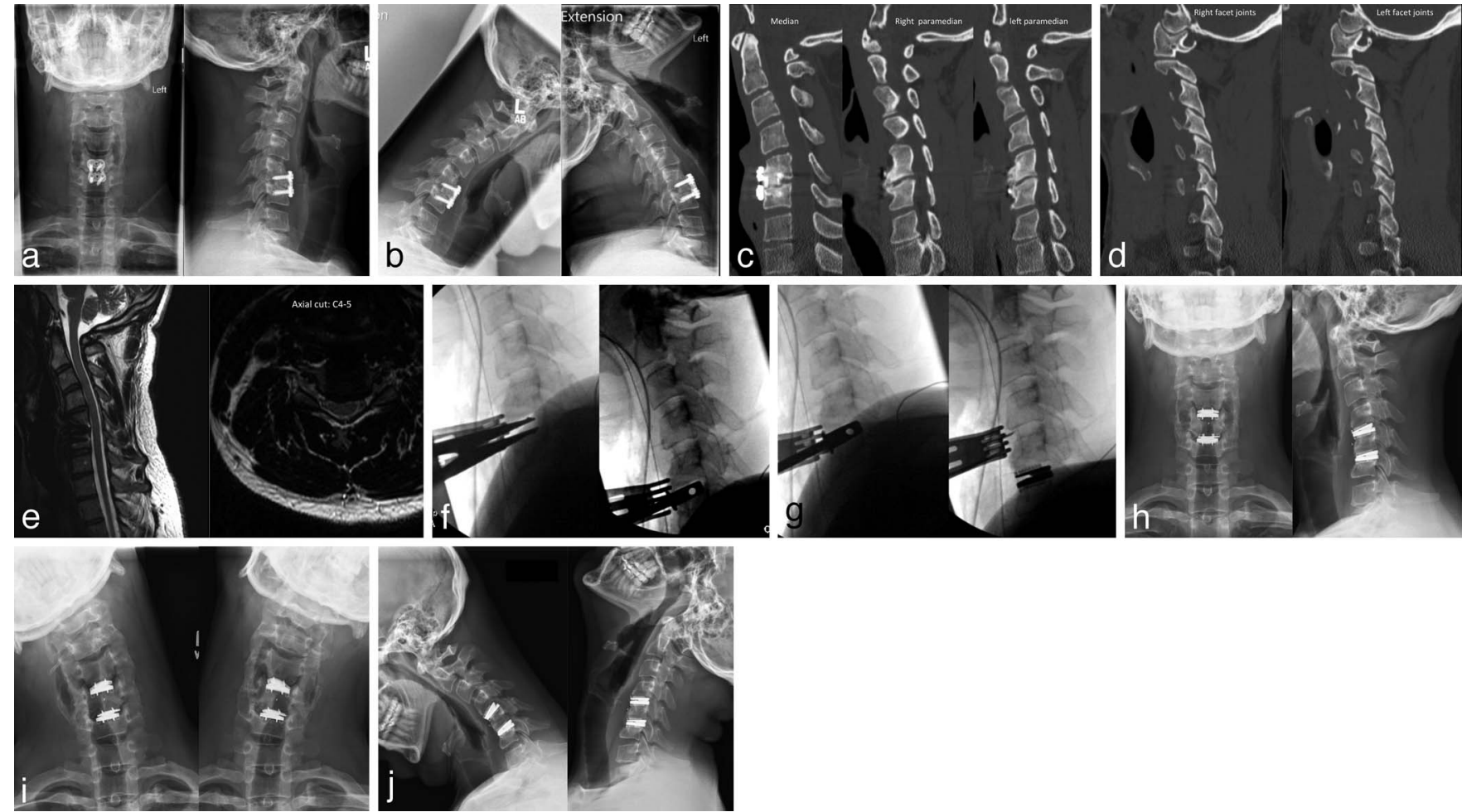

Figure 1. Case example of a 38-year-old male with a pseudoarthrosis at C5-C6 and disc degeneration at C4-C5. Preoperative anterior-posterior (AP), lateral, flexion, and extension radiographs $(\mathrm{a}, \mathrm{b})$. Preoperative computed tomography (CT) cuts through the median sagittal, right paramedian, and left paramedian axes (c) demonstrate pseudoarthrosis. Cuts through the right and left facet joints (d), demonstrating no arthropathy. Preoperative magnetic resonance imaging demonstrates disc degeneration at C4-C5 with left foraminal stenosis (e). Intraoperative fluoroscopic images demonstrate the use of the intradiscal Cloward spreader to open up the disc space after the prior bone graft had been excised using the high-speed drill, followed by trialing (f). Trialing and final artificial disc replacement (ADR) insertion was performed after the disc space was mobilized $(\mathrm{g})$. Postoperative AP, lateral, flexion, extension, and side bending radiographs demonstrate restoration of motion at the C5-C6 level and maintained motion at C4-C5 after ADR $(\mathrm{h}-\mathrm{j})$.

uncovertebral joint in order to widely decompress the foramen, as we believe that this is critical when restoring motion in a previously fused or spondylotic motion segment. After revision decompression was complete and the endplates were parallel, trialing was performed for the artificial disc. The patient was always consented for possible revision fusion in the case that the largest ADR implant was too small for the newly created space. The appropriate size was chosen, the keels were then cut, the disc space was irrigated, and the final implant was impacted into place using biplanar fluoroscopy to determine optimal midline placement and depth. Bone wax was applied to the anterior vertebral bodies, and the wound was then irrigated and closed in layers using 5-0 vicryl. See Figure 1 for a case example.

\section{RESULTS}

The conversion of fusion pseudarthrosis to ADR was successful in all 5 patients without intraoperative or postoperative complication or the need to perform revision fusion. Average patient age was 40 (range 26-62). The average follow-up duration was 12.4 months (range 6-24 months) (see Table 1).

VAS improved on average (median) from 6 (6.0) to $2(2.2)$ at the most recent follow-up. NDI improved on average from 23 (21) to 15 (17). The PROMIS Emotional Distress-Depression Short Form 4a improved from 11 (11) to 4 (4). The PROMIS Pain Interference Short Form $6 \mathrm{~b}$ and PROMIS Physical Function Short Form 10a improved from 23 (22) to 16 (19) and from 37 (35) to 41 (39.5), respectively (Table 2).

Radiographic range of motion on the lateral view increased at the fusion conversion level from an

Table 2. Clinical questionnaires.

\begin{tabular}{lcc}
\hline Questionnaire & $\begin{array}{c}\text { Preoperative: } \\
\text { Mean (Median) }\end{array}$ & $\begin{array}{c}\text { Postoperative: } \\
\text { Mean (Median) }\end{array}$ \\
\hline Neck Disability Index (NDI) & $23(21)$ & $15(17)$ \\
Visual analog pain scale (VAS) & $6(6)$ & $2(2.2)$ \\
PROMIS Emotional Distress & $11(11)$ & $4(4)$ \\
PROMIS Pain Interference & $23(22)$ & $16(19)$ \\
PROMIS Physical Function & $37(35)$ & $41(39.5)$ \\
\hline
\end{tabular}


Table 3. Radiographic angular measurements of motion at the level of conversion from fusion to artificial disc replacement.

\begin{tabular}{llcc}
\hline $\begin{array}{l}\text { Patient Age } \\
\text { and Sex }\end{array}$ & \multicolumn{1}{c}{ Level } & Preoperative & Postoperative \\
\hline 38, male & C5-C6 & 3 & 16 \\
26, male & C5-C6 & 1 & 7.3 \\
37, male & C6-C7 & 0 & 7 \\
62, male & C5-C6, C6-C7 & 1 & 5 \\
38, male & C6-C7 & 0 & 5 \\
Average \pm SD & & $1.0 \pm 1.2$ & $8.1 \pm 4.6$ \\
\hline
\end{tabular}

average of $1.0^{\circ} \pm 1.2^{\circ}$ to $8.1^{\circ} \pm 4.6^{\circ}$ after the insertion of the ADR (Table 3).

\section{CONCLUSIONS}

There are several major concerns when considering a surgical procedure to restore motion at a cervical spine segment at which a fusion or attempted fusion had been previously performed. The indications are controversial. For the current case series, it was performed primarily for pseudoarthrosis with or without adjacent-segment disease where surgical intervention was indicated.

The first obvious concern would be that the facet joint capsules would be contracted and impossible to mobilize after a significant period of immobilization. Some of the patients presented in this series had prior fusion at the level of motion restoration many years ago, and mobilization was still possible. In fact, at surgery, it was found that the facets allowed significant mobility in spite of a long-term fusion indicating that the facet capsules remained functional. It is critical to carefully evaluate the facet joints using thin-cut CT scan to ensure that facet joint ankylosis or severe arthropathy was not present (see Fig. 1c and d for examples). Intraoperatively, a disc space distractor can be used to open and close the disc space repeatedly in order to distract the facet joints and ensure good mobility. Postoperatively, the patients in this series experienced an increase in index level range of motion from an average of $1^{\circ}$ to $8.1^{\circ}$ (Table 3 ). This final outcome range of motion is a similar range of motion observed in other studies of postoperative range of motion after $\mathrm{ADR}$ was performed as the primary surgery. ${ }^{4,6}$

A second major concern prior to attempting a restoration of motion surgery is whether the new disc space size would be too large for the largest size of ADR, which is $7 \mathrm{~mm}$ for the ProDisc and Prestige-LP. In the cases of prior ACDF using PEEK cages, the surgeon must find the interface between the endplate and PEEK, which in pseudarthrosis becomes clear intraoperatively. Lateral fluoroscopy during PEEK extraction is also critical to ensure that the interface is followed without endplate violation and appropriate depth is not exceeded. In the cases presented here, the largest size of implant was often used, and in no cases was this felt to be too loose for implantation.

A third major concern is endplate integrity and bone loss. Preoperative CT scan must be carefully evaluated to ensure that the endplates were not significantly damaged by the prior operation. Additionally, CT scan can reveal not only the pseudarthrosis but also the presence of significant endplate resorption and graft or cage subsidence into the vertebral body. It can be technically challenging to extract interbody cages without creating any endplate damage if significant subsidence occurred. Small osteotomes can be utilized to develop the endplate-graft interface. Caspar pin distraction or intradiscal Cloward distraction can be used to open up the space and assist in graft or cage extraction in the case of pseudarthrosis. Bone grafts used for ACDF are usually not wide enough to fill the entire disc space laterally, so wide exposure and additional discectomy can be used to find the native endplate on either side of the bone graft. The highspeed bur is then used to drill the graft in a lateral to medial direction along the native endplate, resecting bone graft and interbody fusion without violating the endplate and vertebral body. This should be monitored carefully under lateral fluoroscopy. In addition, the vertebral artery must be protected during wide lateral dissection.

All patients in this case report series experienced a significant improvement in their pain and function as determined by NDI, VAS, and PROMIS questionnaires (Table 2). While one must take caution in reporting follow-up data of only 1-year duration, the durability of neurologic and pain relief success has been extensively demonstrated by many randomized controlled trials evaluating ADR. Radiographically, we have not found any subsidence of the converted levels with the artificial disc implants. It must be noted that the largest footprint available of the implant was used in the restorative motion levels. The current set of patients should not be any different once the disc replacement has been successfully implanted. If significant postoperative implant subsidence were to occur, it would most likely occur within the first 3 months postoperatively. 


\section{REFERENCES}

1. Burkus JK, Haid RW, Traynelis VC, et al. Long-term clinical and radiographic outcomes of cervical disc replacement with the Prestige disc: results from a prospective randomized controlled clinical trial. J Neurosurg. 2010;13:308-318.

2. Burkus JK, Traynelis VC, Haid RW Jr, et al. Clinical and radiographic analysis of an artificial cervical disc: 7-year followup from the Prestige prospective randomized controlled clinical trial: clinical article. J Neurosurg. 2014;21:516-528.

3. Mummaneni PV, Burkus JK, Haid RW, et al. Clinical and radiographic analysis of cervical disc arthroplasty compared with allograft fusion: a randomized controlled clinical trial. $J$ Neurosurg. 2007;6:198-209.

4. Janssen ME, Zigler JE, Spivak JM, et al. ProDisc-C total disc replacement versus anterior cervical discectomy and fusion for single-level symptomatic cervical disc disease: seven-year follow-up of the Prospective Randomized U.S. Food and Drug Administration Investigational Device Exemption Study. $J$ Bone Jt Surg. 2015;97:1738-1747.

5. Zigler JE, Delamarter R, Murrey D, et al. ProDisc-C and anterior cervical discectomy and fusion as surgical treatment for single-level cervical symptomatic degenerative disc disease: fiveyear results of a Food and Drug Administration study. Spine (Phila Pa 1976). 2013;38:203-209.

6. Lanman TH, Burkus JK, Dryer RG, et al. Long-term clinical and radiographic outcomes of the Prestige LP artificial cervical disc replacement at 2 levels: results from a prospective randomized controlled clinical trial. J Neurosurg. 2017;27:7-19.

7. Phillips FM, Geisler FH, Gilder KM, et al. Long-term outcomes of the US FDA IDE prospective, randomized controlled clinical trial comparing PCM cervical disc arthroplasty with anterior cervical discectomy and fusion. Spine (Phila Pa 1976)2015;40:674-683.

8. Cheng L, Nie L, Li M, et al. Superiority of the Bryan $\left({ }^{\circledR}\right)$ disc prosthesis for cervical myelopathy: a randomized study with 3-year followup. Clin Orthop. 2011;469:3408-3414.

9. Davis RJ, Nunley PD, Kim KD, et al. Two-level total disc replacement with Mobi-C cervical artificial disc versus anterior discectomy and fusion: a prospective, randomized, controlled multicenter clinical trial with 4-year follow-up results. $J$ Neurosurg. 2015;22:15-25.

10. Vaccaro A, Beutler W, Peppelman W, et al. Long-term clinical experience with selectively constrained secure-c cervical artificial disc for 1-level cervical disc disease: results from sevenyear follow-up of a prospective, randomized, controlled investigational device exemption clinical trial. Int J Spine Surg. 2018;12:377-387.

11. Hilibrand AS, Robbins M. Adjacent segment degeneration and adjacent segment disease: the consequences of spinal fusion? Spine J. 2004;4:190S-194S.

12. Gornet MF, Burkus JK, Shaffrey ME, et al. Cervical disc arthroplasty: 10-year outcomes of the Prestige LP cervical disc at a single level. J Neurosurg. 2019;31:1-9.

13. $\mathrm{Xu} \mathrm{S}$, Liang $\mathrm{Y}$, Zhu $\mathrm{Z}$, et al. Adjacent segment degeneration or disease after cervical total disc replacement: a meta-analysis of randomized controlled trials. J Orthop Surg Res. 2018;13:244.

14. Hung M, Hon SD, Franklin JD, et al. Psychometric properties of the PROMIS physical function item bank in patients with spinal disorders. Spine (Phila Pa 1976). 2014;39:158-163.

15. Boody BS, Bhatt S, Mazmudar AS, et al. Validation of Patient-Reported Outcomes Measurement Information System (PROMIS) computerized adaptive tests in cervical spine surgery. J Neurosurg. 2018;28:268-279.

Disclosures and COI: Jason Cuellar: Consultant for Centinel Spine, Aegis Spine, Carestream and Cytonics Corporation. Todd Lanman: Consulting and Royalties for Medtronic, Nuvasive, Stryker, Choice Spine.

Corresponding Author: Jason M. Cuellar, $\mathrm{MD}, \mathrm{PhD}, 450$ North Roxbury Drive, Third Floor, Beverly Hills, CA 90210. Phone: (310) 385-7766; Email: cuellarj@gmail.com.

Published 28 August 2020

This manuscript is generously published free of charge by ISASS, the International Society for the Advancement of Spine Surgery. Copyright (c) 2020 ISASS. To see more or order reprints or permissions, see http://ijssurgery.com. 